International Journal of Current Advanced Research

ISSN: O: 2319-6475, ISSN: P: 2319 - 6505, Impact Factor: SJIF: 5.995

Available Online at www.journalijcar.org

Volume 6; Issue 3; March 2017; Page No. 2668-2670

DOI: http://dx.doi.org/10.24327/ijcar.2017.2670.0071

Research Article

\title{
KNOWLEDGE, AWARENESS AND PRACTICE OF TOOTH POLISHING AGENTS AMONG DENTAL PRACTITIONERS
}

\author{
Sarvesh Kumar J*., Dhanraj and Anandhi
}

Department of Prosthodontics, Saveetha Dental College, 162, P.H Road, Chennai, Tamilnadu 600077

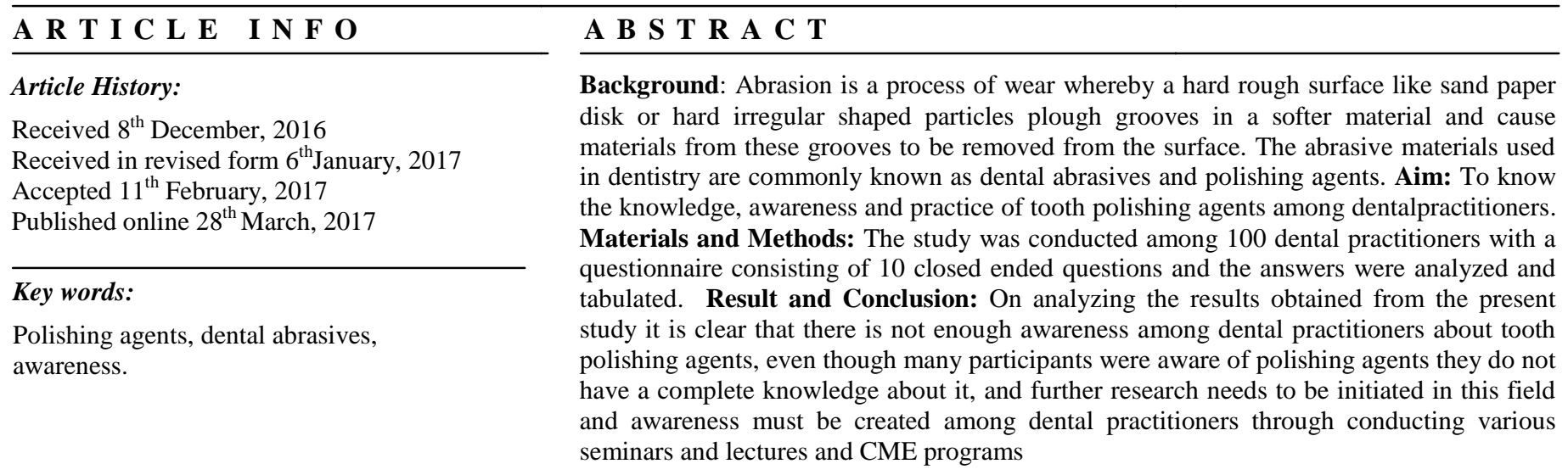

Copyright@2017 Sarvesh Kumar J., Dhanraj and Anandhi. This is an open access article distributed under the Creative Commons Attribution

License, which permits unrestricted use, distribution, and reproduction in any medium, provided the original work is properly cited.

\section{INTRODUCTION}

Tooth polishing is done to smooth the surfaces of teeth and restorations. ${ }^{[1]}$ The purpose of polishing is to remove extrinsic stains, remove dental plaque accumulation, increase aesthetics and to reduce corrosion of metallic restorations. ${ }^{[2]}$ Tooth polishing has little therapeutic value and is usually done as a cosmetic procedure after debridement and before fluoride application. ${ }^{[3]}$ Effective finishing and polishing of dental restorations not only result in optimal aesthetics but also provide for acceptable oral health of soft tissues and marginal integrity of the restorative interface ${ }^{[4]}$ Abrasive materials are mainly minerals which are used in Finishing and Polishing a Restoration, Abrasive materials are used to remove the uneven or rough surface on the surface of restorative materials which will lead to debris accumulation and decrease the surface smoothness. ${ }^{[5]}$ These Dental Abrasive material particles coat the surface of the burs and act on the tooth or restorative materials by rotation of the bur using a hand piece. Some abrasive materials are used in the form of paste and others as Polishing Strips.The commonly used Abrasive materials in Dentistry are:Natural Diamond: Used for Ceramic and Resin based composite materials Synthetic Diamond: Used on Tooth Structures, Ceramic materials and Resin based composite materialsArkansas Stone: For fine grinding of tooth enamel and metal alloysChalk:

*Corresponding author: Sarvesh Kumar J, Department of Prosthodontics, Saveetha Dental College, 162, P.H Road, Chennai, Tamilnadu 600077
To polish tooth enamel, gold foil, amalgam and plastic materials Corundum (White Stone): For grinding metal alloys Abrasives: On Composite materialsEmery: For finishing metal alloys or acrylic resinGarnet: For Grinding metal alloys and acrylic resin materialsPumice: Polishing tooth enamel, gold foil, dental amalgam and acrylic resinsQuartz: Finish metal alloys and to grind dental enamelSand: Grinding of metal alloys and acrylic resin materialsZirconium Silicate: Component of dental prophylaxis paste and Cuttle: Polishing of metal margins and dental amalgam restorations. ${ }^{[6]}$

\section{METHODS}

- The study was conducted among 100 dental practitioners.

- A questionnaire containing 10 close ended questions wasprepared and given to theparticipants for filling up.

- Answers were analyzed and evaluated results obtained were tabulated in bar graphs

\section{Questionnaire}

1. Are you aware about tooth polishing agents

[] Yes

[ ] No

2. Do have enough knowledge about tooth polishing agents

[] Yes

[] No

3. Do you use tooth polishing agents 


\section{[ ] Yes}

[ ] No

4. From where did you get information about tooth polishing agents

[ ] Curriculum

[ ] Internet

[] Friends

[ ] Books

5. Do you think tooth polishing agents are effective

[] Yes

[ ] No

6. What are the tooth polishing agents you are aware of (can choose multiple options)

[ ] Silex (silex dioxide)

[] Pumice

[ ] Calcium carbonate

[ ] Tin oxide

[ ] Emery

[ ] Rouge

[ ] Diamond particles

[ ] None

7. Why do you think tooth polishing agents are used mostly (can choose multiple options)

[ ] Remove stains

[ ] Remove dental plaque

[ ] Promote oral hygiene

[ ] Increase aesthetics

[ ] Reduce corrosion of metallic restorations

Do tooth polishing agents erode enamel

[] Yes

[] no

[ ] Not sure

8. Polishing agents when ingested by mistake do they cause harmful effects

[ ] Yes

[] No

[ ] Not sure

9. Can polishing agents stay in restorations

[ ] Yes

[] No

[ ] not sure

\section{RESULT}

From the study we could infer that $30 \%$ of the participants say they do not have enough knowledge about polishing agents from graph 1, and $20 \%$ of the participants are not even familiar with polishing agents from graph 1, only $50 \%$ of participants think that polishing agents are effective in use from graph $2.30 \%$ of the participants say polishing agents cause harm on ingestion but excess amount of anything ingested will cause harm from graph 6 whereas when minute quantities are ingested they will not cause much harm to the body. More than $35 \%$ of the participants are aware of pumice as a tooth polishing agents and $22 \%$ of the participants are aware calcium carbonate, $10 \%$ of the participants are aware of diamond particles and rouge and only $5 \%$ of the participants are aware about emery, tin oxide and rouge from graph 3. $40 \%$ of the participants think use of polishing agents cause erosion of enamel from graph 4 and $20 \%$ of participants think polishing agents stay in restorations from graph $5.55 \%$ of the participants say polishing gents are used to increase aesthetics, $18 \%$ of participants say polishing agents are used to remove dental plaque and reduce corrosion of metallic restorations from graph $8.35 \%$ of the population do not use polishing agents in practice from graph 7 .
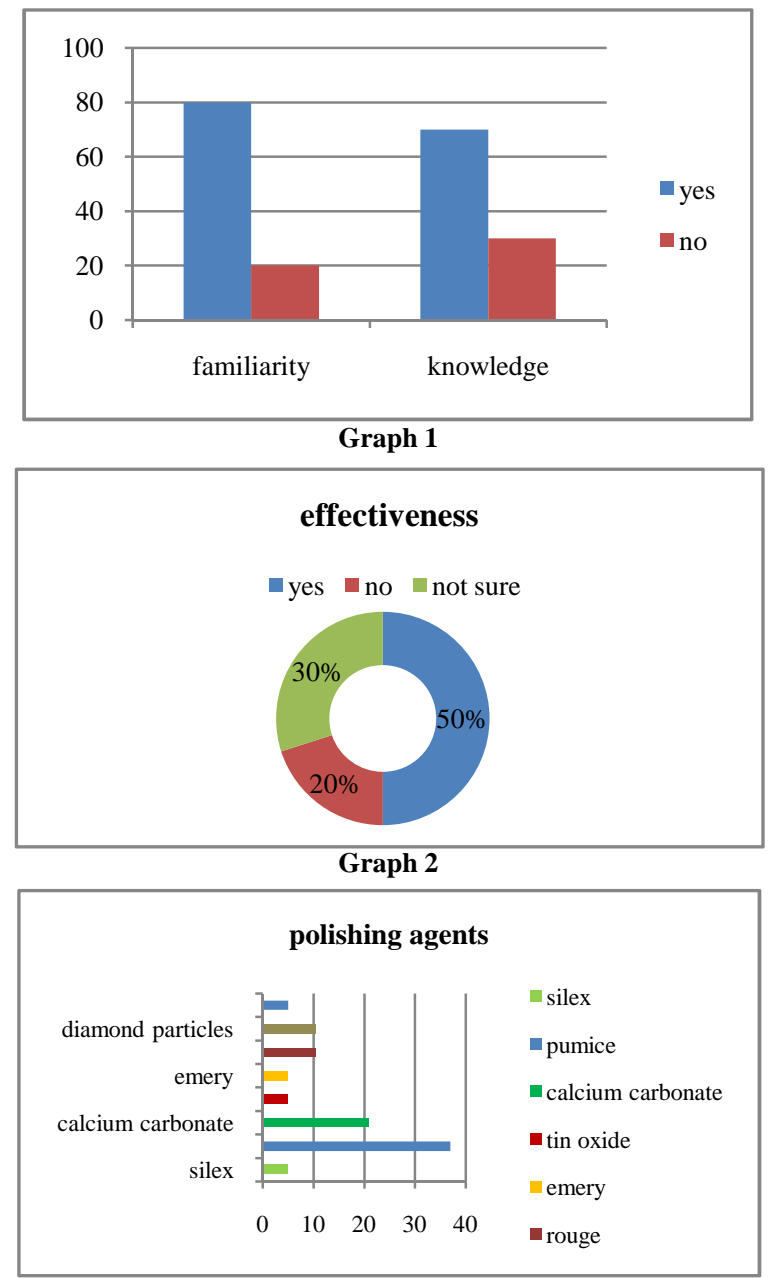

Graph 3

erosion of enamel

घes $\square$ no $\square$ not sure

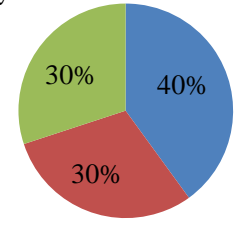

Graph 4

stay in restorations

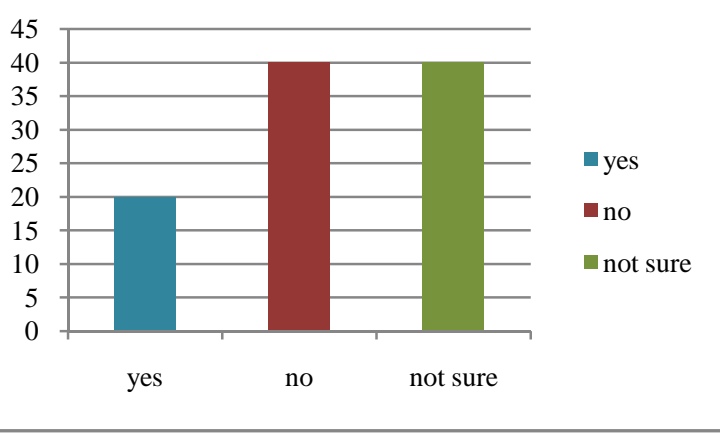

Graph 5 

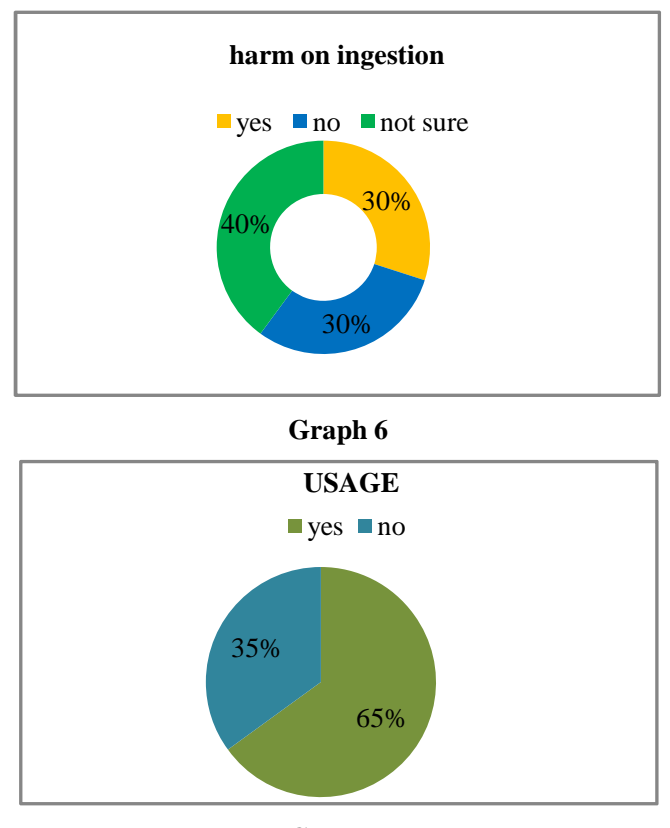

Graph 7

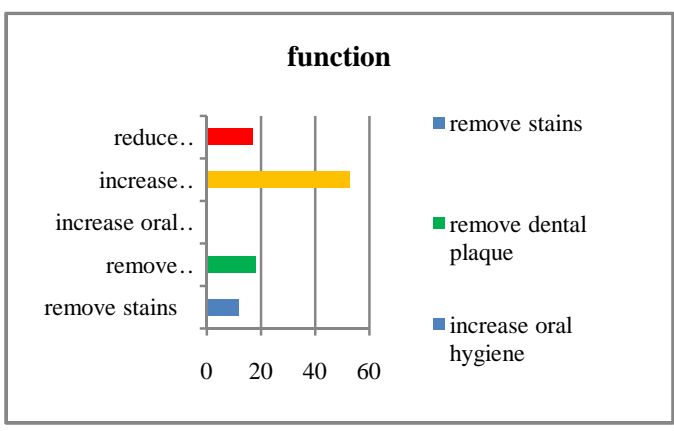

Graph 8

\section{DISCUSSION}

James et.al in their research said that After the gross reduction and fine finishing of a composite resin restoration, selecting a system to create the smoothest polish is difficult because high magnification is necessary to compare the surface roughness. ${ }^{[7]}$ Kwok et.al in thier study said that polishing procedures produced a decrease in the roughness, ranging from 26 to $74 \%$. Relative to the shade guide, the mean color difference values for all the composites after polishing were significantly greater than for the controls $(\mathrm{p} \leq 0.01)$ and ranged from 1.08 to 8.15 units. ${ }^{[8]}$ Andre et.al in their study said that significant differences were found for the surface roughness and staining, with interaction among composite resins and the finishing systems. ${ }^{[9]}$ Duygu et. al in their study said the polishing technique and type of composite resin significantly affected the surface roughness of the composite resins $(P<.001)$. While the use of polishing wheels produced the highest surface roughness values when compared to the other polishing techniques $(P<.001)$, the nanohybrid composite resin showed the lowest surface roughness values compared to the other composite resins ${ }^{[10]}$ Heintze et.al in their study explained that polishing the surface with a polishing machine resulted in a significantly better surface gloss in all materials. ${ }^{[11]}$ Sibel.et.al in their study said that different finishing polishing systems provided comparable surface smoothness for composites ${ }^{[12]}$

\section{CONCLUSION}

On analyzing the results obtained from the present study it is clear that there is not enough awareness among dental practitioners about tooth polishing agents, even though many participants were aware of polishing agents they do not have a complete knowledge about it, and further research needs to be initiated in this field and awareness must be created among dental practitioners through conducting various seminars and lectures and CME programs

\section{References}

1. Jones, Trish (July 2016). "Selective Polishing: An Approach to Comprehensive Polishing". www.Rdh mag.com. PennWell Publications.

2. Stewart, Marcia; Bagby, Michael (2013). Clinical Aspects of Dental Materials: Theory, Practice, and Cases. Philadelphia: Lippincott Williams \& Wilkins. pp. 205-222. ISBN 978-1-60913-965-0

3. "American Dental Hygienists' Association Position Paper on the Oral Prophylaxis".www.adha.org. American Dental Hygienists' Association. April29, 1998.

4. Jefferies, Steven R. "Abrasive Finishing and Polishing in Restorative Dentistry: A State-of-the-Art Review." Dental Clinics of North America 51.2 (2007): 379-97. Web.

5. Chung, Kwok-Hung. "Effects of finishing and polishing procedures on the surface texture of resin composites." Dental Materials 10.5 (1994): 325-30. Web.

6. Stoddard, James W., and Glen H. Johnson. "An evaluation of polishing agents for composite resins." The Journal of Prosthetic Dentistry 65.4 (1991): 491-95. Web.

7. James W. Stoddard D.D.S.Glen H. Johnson D.D.S., M.S. An evaluation of polishing agents for compositeresins The Journal of Prosthetic Dentistry April 1991, Vol.65 (4):491495, doi:10.1016/00223913(91)90286-6

8. Kwok-hung Chung; Effects of finishing and polishing procedures on the surface texture of resin composites; http://dx.doi.org/10.1016/0109-5641(94)90041-8

9. André F Reis ${ }^{\mathrm{a}, \text {, }}$ Marcelo Giannini ${ }^{\mathrm{a}}$, José R Lovadino $^{\mathrm{a}}$, Gláucia M Ambrosano ${ }^{\mathrm{b}}$ Effects of various finishing systems on the surface roughness and staining susceptibility of packable composite resins http://dx.doi.org/10.1016/S0109-5641(02)00014-3

10. Duygu Sarac, DDS, PhD', Y. Sinasi Sarac, DDS, PhD, Safak Kulunk, DDS, Cagri Ural, DDS, Tolga Kulunk, DDS; The effect of polishing techniques on the surface roughness and color change of composite resins; http://dx.doi.org/10.1016/j.prosdent.2006.04.01 2

11. S.D. Heintze, M. Forjanic, V. Rousson Surface roughness and gloss of dental materials as a function of force and polishing time in vitro; http://dx.doi.org/ 10.1016/j.dental.2005.04.013

12. Sibel A. Antonson ${ }^{\mathrm{a},}$, A. Rüya Yazici ${ }^{\mathrm{b}, 1,}$ Evren Kilinc $^{\text {c, 2, }}$ Donald E. Antonson ${ }^{\mathrm{a}, 3,}$, Patrick C. Hardigan ; Comparison of different finishing/polishing systems on surface roughness and gloss of resin composites; http://dx.doi.org/10.1016/j.jdent.2011. 01.006 